\title{
Становление национальной системы квалификаций и государственных стандартов высшего образования
}

О.н. поповА, кандидат педагогических наук, Технологический институт филиал Национального исследовательского ядерного университета «МИФИ», г. Лесной. E-mail: onpopova49@mail.ru

В статье анализируются тенденции развития высшего образования. Обсуждаются вопросы особенностей сопряжения профессиональных и образовательных стандартов, введение демонстрационного квалификационного экзамена в качестве итоговой формы практико-ориентированного обучения, вовлечения студентов в процесс WorldSkills Russia.

Ключевые слова: квалификация; федеральные государственные образовательные стандарты; профессиональные стандарты; ФГОС 3++; национальная система квалификаций; примерная основная образовательная программа; основная профессиональная образовательная программа; демонстрационный квалификационный экзамен

Высшая школа вновь на пороге изменений. Российские вузы с 1 января 2019 г. должны приступить к подготовке студентов по актуализированным федеральным государственным образовательным стандартам (ФГОС $3++$ ). Напомним, что его приведение в соответствие профессиональным стандартам необходимо было закончить до 1 июля 2017 г., т.е. в течение одного года со дня вступления в силу Ф3 № 122 от 02.05.2015 г.

Педагогическое сообщество обеспокоено: как за столь короткий срок выполнить «актуализацию» неутвержденных ФГОС 3++ при отсутствии примерных основных образовательных программ (ПООП), при этом обеспечить подготовку основных профессиональных образовательных программ (ОПОП) и комплексов учебно-методических материалов? О каком качестве предстоящей работы в таких условиях можно говорить?

Сама идея, безусловно, отвечает насущным потребностям. Актуальнейшей задачей является развитие системы профессионального образования, обеспечивающее высокое качество образовательного практико-ориентированного процесса и, как следствие, достойный уровень подготовки кадров. Запрос работодателя такой: 
выпускник должен демонстрировать не столько свои знания, сколько умения и навыки. Как эти умения и навыки обеспечить, чтобы они были востребованы работодателем?

Требования, предъявляемые рынком труда к квалификации претендентов на вакансию и к компетенциям выпускников, должны быть «гармонизированы», т.е. сопряжены и согласованы «через национальную рамку квалификаций ....» [Караваева, 2017. С. 6]. Вместе с тем отмечается, что «образовательные организации с самого начала не были включены в процесс формирования Национальной системы квалификаций, педагогическое сообщество до сих пор играет в этом процессе пассивную роль, фактически только исполняя принятые решения. Данное обстоятельство привело к тому... что не создана единая модель требований...».

Впрочем и сама Национальная система квалификаций только строится, формируется «новый правовой и методологический базис сферы труда с системой высшего образования» [Шехонин и др., 2017. С. 5]. Очевидно, что процесс слишком затянулся.

Затруднения связаны, прежде всего, с несогласованностью требований профессиональных и образовательных стандартов. Сформировать требования к профессиональным компетенциям выпускника с учетом профессиональных стандартов не всегда представляется возможным по объективным причинам. Профессиональный стандарт оперирует обобщенными и трудовыми функциями, т.е. требованиями к работнику, исходя из существующей ситуации (в настоящее время). Образовательный же стандарт должен формировать у выпускника требуемые компетенции в связи с востребованностью их на рынке труда после завершения обучения, т.е. в будущем. Не получится ли так, что вуз будет готовить студента под потребности работодателя сегодняшнего дня, а требования рынка за это время изменятся?

На основании анализа процесса выполнения согласования профессиональных и образовательных стандартов сложилось понимание, что «сопряжение... не работает в той степени, в которой ожидалось» [Кузьминов, 2016. С. 2]. Возникло понимание, что фактически невозможно в процессе разработки образовательных стандартов учесть все результаты образования «ввиду постоянного изменения науки, технологий..., появления новых профессиональных стандартов» [Кузьминов, 2016. С. 2]. 
Другой пласт проблем связан с созданием механизма сохранения единого образовательного пространства России. Предполагается что «в обязательной части ПООП будут прописаны не только компетенции, но и индикаторы достижения компетенций» [Романов, 2016. С.11]. Кто же будет разрабатывать процедуру контроля выполнения этих индикаторов, и какими средствами он будет осуществляться? Пока четкого ответа не просматривается. Предполагается внесение изменений в государственную систему оценки качества, аккредитации и лицензирования в соответствии с требованиями ФГОС 3++, введение профессионально-общественной аккредитации, методологию и формы проведения которой еще предстоит сформировать. Ответственными за разработку ФГОС 3++ и подготовку примерных программ (ПООП) являются федеральные учебно-методические объединения. В соответствии с концепцией структуры ФГОС $3++$ стандарты все в большей степени носят рамочный характер. Профессиональные компетенции будут перенесены в ПООП, а на откуп вузам отдается разработка основных программ (ОПОП) на основе ФГОС с учётом примерных программ.

В связи с вышеизложенным в ближайшей перспективе итоговой процедурой контроля качества обучения, наряду с выполнением выпускной квалификационной работы, для выпускников вузов должен стать практико-ориентированный квалификационный экзамен. Ряд вузов уже имеют опыт проведения «пробных» демонстрационных квалификационных экзаменов. С позиции работодателя такой экзамен может служить определенным критерием качества квалификации выпускника. Ведь на выпускную квалификационную работу бакалавров в соответствии со стандартом выделяется 6-9 недель вместе с процедурой предварительной защиты, времени на отзыв эксперта и саму защиту. Тем не менее говорить о выполнении выпускником полноценной квалификационной работы не приходится.

Кроме того, в качестве практико-ориентированного обучения вузы включаются в процесс WorldSkills Russia. Изначально это движение направлено на развитие системы подготовки рабочих кадров и кадров среднего профессионального образования. Однако есть ряд направлений подготовки бакалавров, когда студенты в процессе обучения могут принимать участие в WorldSkills Russia и демонстрировать свои умения. Это позволяет им получать 
более достоверную информацию о реальной ситуации на рынке труда и предъявляемых требованиях, спросе на профессии и компетенции.

Включение демонстрационного квалификационного экзамена в процедуру государственной итоговой аттестации может рассматриваться как часть объективной модели независимой оценки качества подготовки выпускников.

При разработке содержательной стороны экзамена необходимо учитывать, что выпускник высшей школы не должен демонстрировать свои «навыки»: они достаточно быстро «нарабатываются», это поле деятельности рабочих профессий. Приоритетная же задача вуза - подготовка мыслящего (хорошо бы нестандартно и творчески) будущего специалиста. В этом смысле использование шаблонного по форме экзамена, аналога критикуемого ЕГЭ, может принести больше вреда, чем пользы.

Главное, чтобы квалификационный экзамен не привел к «натаскиванию» студента, как это происходило при подготовке к интернет-экзаменам по целому ряду дисциплин, в том числе и непрофильным. Это ведь тоже было «пережито» вузами. Преподавательский состав высшей школы в полной мере прочувствовал уровень школьной подготовки первокурсников после введения ЕГЭ. Так называемое «клиповое» мышление, неумение рассуждать, обосновывать своё решение, формулировать выводы осложняет формирование важнейших умений выпускников вузов.

Следует признать, что образовательный процесс требует осознанной стабильности. В реальности же высшее образование «преобразуется» не первый год, и обнадеживающих признаков разумного завершения «изысканий» в ближайшей перспективе пока не предвидится. Одно перечисление наименований стандартов последних лет впечатляет: ГОС (первого и второго поколения), ФГОС, ФГОС 3, ФГОС 3+, ФГОС 3++. С какими только проблемами за последние годы высшая школа не сталкивалась, о чём свидетельствуют многочисленные публикации [см., например, Попова, 2015. С.167].

Проделанный объем учебно-методической работы и объем подготовленной, порой бессмысленной документации повергает преподавательский состав в уныние... Сколько труда вложено, а успехов не просматривается. «Бумаготворчество», накрывшее высшую школу, снижение «контактной работы» (термин, 
введенный вместо понятия «аудиторной работы»), в том числе и требования к «научному творчеству», не оставляют времени на разумное осмысление содержательной стороны основной деятельности.

Фактическая подготовка к введению стандарта ФГОС 3++ затягивается во многих случаях по не зависящим от вузов причинам. Надеяться, что в установленные сроки можно грамотно выполнить данную работу, не приходится. Как результат - высшее образование лихорадит...

В условиях, когда всё имеет свою цену, и, прежде всего, такой невосполнимый ресурс, как время, распоряжаться им надо разумно, продумывая последствия принимаемых, хорошо бы, оптимальных решений. Некоторые вузы предпринимают шаги по решению данной проблемы, однако в системе распределенного (сетевого) университета, работающего по своим стандартам, для его филиальной сети поставленные задачи на порядок сложнее (в перспективе ФГОС 3++, ПООП и, видимо, свои стандарты). Нас, участников очередной реорганизации системы высшего образования, ждут «новые вызовы, новые преобразования и новые перспективы» [Материалы, 2018. С. 1].

\section{Литература}

Караваева Е. В. Квалификация высшего образования и профессиональные квалификации: «сопряжение с напряжением» // Высшее образование в России. 2017. № 12 (218). С. 5-12.

Кузьминов Я.В. Применение профессиональных стандартов при актуализации ФГОС профессионального образования и формировании примерных основных образовательных программ: особенности и ограничения [Эл. ресурс]. URL: http://mgudt.ru/filemanag/Uploads/umo/2016-12-12/2/Я.И.Кузьминов.pdf (дата обращения: 06.04.2018).

Материаль семинара 22-23 марта 2018 «ФГОС ВО 3++: Профессиональные стандарты, аккредитация, лицензирование» [Эл. ресурс]. URL: http:/ vseprofi24.ru/\%D1\%84\%D0\%B3\%D0\%BE\%D1\%81/ (дата обращения 05.04.2018).

Попова О.Н. На пути к новым стандартам высшего образования // ЭКО. 2015. № 10. С. 167-171.

Прокопьев Ф. T. Национальная система квалификаций: что мы строим [Эл. pecypc]. URL: http://npirf.ru/nacionalnaya-sistema-kvalifikacij-chto-my-stroim/ (дата обращения: 19.03.2018).

Романов П.И. Проектирование основных профессиональных образовательных программ на основе профессиональных стандартов и иных требований рынка труда [Эл. ресурс]. URL: http:/www.mgudt.ru/filemanag/Uploads/ umo/2016-12-12/2/П.И.Романов.pdf (дата обращения: 19.03.2018). 
Шехонин А.А., Тарлыков В.А., Вознесенская А. О., Бахолдин А. В. Гармонизация квалификаций в системе высшего образования и в сфере труда // Высшее образование в России. 2017. № 11 (217). С. 5-11.

Статья поступила 17.08.2018.

\section{Summary}

Popova O.N., Institute of Technology-branch of the National Research Nuclear University MEPhI», Lesnoy

Problems of Formation of the National System of Qualifications and Updating of Federal State Educational Standards of Higher Education

The article analyzes the tendencies of development of higher education. The article discusses the features of the interface of professional and educational standards, the introduction of a demonstration qualification exam as a final form of practice-oriented learning, the involvement of students in the process WorldSkills Russia.

Graduate's qualification; federal state educational standards; professional standards; FSES3++; national qualification system; approximate basic educational program; basic professional educational program; demonstration of qualification exam

\section{References}

Karavaeva E.V. (2017). Qualification of higher education and professional qualifications: "conjugation with tension". Higher education in Russia. No. 12 (218). Pp. 5-12. (In Russ.)

Kuzminov Ya.V. (2016). Application of professional standards in updating the FSES vocational education and the formation of exemplary basic educational programs: features and imitations. Available at: http://mgudt.ru/filemanag/Uploads/ umo/2016-12-12/2/Я.И.Кузьминов.pdf (accessed 06.04.2018). (In Russ.)

Proceedings of the seminar March 22-23, 2018 «FSES3++: Professional standards, accreditation, licensing». Available at: http://vseprofi2 4. $\mathrm{ru} / \% \mathrm{D} 1 \% 84 \% \mathrm{D} 0 \% \mathrm{~B} 3 \% \mathrm{D} 0 \% \mathrm{BE} \% \mathrm{D} 1 \% 81 /$ (accessed 05.04.2018). (In Russ.)

Popova O.N. (2015). On the way to new standards of higher education. ECO. [ECO]. No. 10. Pp. 167-171. (In Russ.)

Prokopev F. T. National qualifications framework: what we build. Available at: http://npirf.ru/nacionalnaya-sistema-kvalifikacij-chto-my-stroim (accessed 19.03.2018). (In Russ.)

Romanov P.I. (2016). Design of the main professional educational programs on the basis of professional standards and other requirements of the labor market. Available at: http://www.mgudt.ru/filemanag/Uploads/umo/2016-12-12/2/ П.И.Романов.pdf. (accessed 19.03.2018). (In Russ.)

Shekhonin A.A., Tarlykov V.A., Voznesenskaya A. O., Bakholdin A. V. (2017). Harmonization of qualifications in higher education and in the labor sphere. Higher education in Russia. No.11 (217). Pp. 5-11. (In Russ.) 